\title{
Biliary-duodenal anastomosis using magnetic compression following massive resection of small intestine due to strangulated ileus after living donor liver transplantation: a case report
}

Ryusuke Saito, Hiroyuki Tahara*, Seiichi Shimizu, Masahiro Ohira, Kentaro Ide, Kohei Ishiyama,

Tsuyoshi Kobayashi and Hideki Ohdan

\begin{abstract}
Background: Despite the improvements of surgical techniques and postoperative management of patients with liver transplantation, biliary complications are one of the most common and important adverse events. We present a first case of choledochoduodenostomy using magnetic compression following a massive resection of the small intestine due to strangulated ileus after living donor liver transplantation.

Case presentation: The 54-year-old female patient had end-stage liver disease, secondary to liver cirrhosis, due to primary sclerosing cholangitis with ulcerative colitis. Five years earlier, she had received living donor liver transplantation using a left lobe graft, with resection of the extrahepatic bile duct and Roux-en-Y anastomosis. The patient experienced sudden onset of intense abdominal pain. An emergency surgery was performed, and the diagnosis was confirmed as strangulated ileus due to twisting of the mesentery. Resection of the massive small intestine, including choledochojejunostomy, was performed. Only $70 \mathrm{~cm}$ of the small intestine remained. She was transferred to our hospital with an external drainage tube from the biliary cavity and jejunostomy. We initiated total parenteral nutrition, and percutaneous transhepatic biliary drainage was established to treat the cholangitis. Computed tomography revealed that the biliary duct was close to the duodenum; hence, we planned magnetic compression anastomosis of the biliary duct and the duodenum. The daughter magnet was placed in the biliary drainage tube, and the parent magnet was positioned in the bulbus duodeni using a fiberscope. Anastomosis between the left hepatic duct and the duodenum was accomplished after 25 days, and the biliary drainage stent was placed over the anastomosis to prevent re-stenosis. Contributions to the successful withdrawal of parenteral nutrition were closure of the ileostomy in the adaptive period, preservation of the ileocecal valve, internal drainage of bile, and side-to-side anastomosis.
\end{abstract}

Conclusions: Choledochoduodenostomy with magnet compression could be a less invasive and safer method for treatment of biliary stricture that cannot be accessed by conventional surgery.

Keywords: Primary sclerosing cholangitis, Living donor liver transplantation, Magnetic compression anastomosis, Choledochoduodenostomy, Short bowel syndrome

\footnotetext{
* Correspondence: htahara@hiroshima-u.ac.jp

Department of Gastroenterological and Transplant Surgery, Hiroshima

University, 1-2-3 Kasumi, Minamiku, Hiroshima, Hiroshima 734-8551, Japan
} 


\section{Background}

Primary sclerosing cholangitis (PSC) is a chronic cholestatic disease characterized by the progressive fibrosing inflammatory destruction of the intrahepatic and extrahepatic ducts, leading to liver failure [1]. PSC is the sixth most common cause of the liver transplantation in Japanese adults, following neoplastic diseases, primary biliary cirrhosis, hepatitis $C$ virus cirrhosis, hepatitis $B$ virus cirrhosis, and alcoholic cirrhosis [2]. The recipient's common bile duct is certainly resected, and hepatocholangiojejunostomy is needed in the case of liver transplantation for PSC.

Historically, surgery has been the standard treatment for biliary stricture. However, surgery may be too invasive for elderly patients or patients with a poor general and nutritional condition. Repeat surgeries for biliary stricture are difficult because of the high risk of vascular complications near the anastomosis, postoperative adhesions, and inflammatory changes [3]. There is also a risk of inflammation of the anastomosis caused by foreign bodies, such as stitches or clips [4]. However, magnetic compression anastomosis (MCA) is a less invasive and safer procedure than choledochoenterostomy or choledochocholedochostomy for a biliary stricture or obstruction, with a low rate of complications and re-stenosis [5]. This procedure is also used for biliary stricture after liver transplantation or palliation of obstructive jaundice for malignancies $[4,6]$. Several reports have demonstrated the superiority of internal over external biliary drainage in terms of intestinal barrier, integrity, absorption of nutrition, and liver function $[7,8]$.

Here, we report a first case of choledochoduodenostomy managed with magnetic compression following a massive resection of the small intestine due to strangulated ileus after living donor liver transplantation (LDLT).

\section{Case presentation}

The patient was a 54-year-old Chinese woman with a history of PSC and ulcerative colitis (UC). She had received LDLT using a left lobe graft, with resection of the extrahepatic bile duct and Roux-en-Y anastomosis for end-stage liver disease due to PSC. Her UC was well controlled with aminosalicylates and methylprednisolone. Cholangitis had reoccurred, but she had never previously experienced ileus in the postoperative period.

The patient was referred to a hospital in China with sudden onset of intense abdominal pain. A strangulated ileus due to internal hernia was highly suspected, and an emergency surgery was performed. Laparotomy revealed muddy massive ascites and necrotic intestine due to twisting of the mesentery. Resection of the massive small intestine, including choledochojejunostomy, was performed, with only $70 \mathrm{~cm}$ of the small intestine remaining. She was transferred to our hospital with an external drainage tube of the biliary cavity and a jejunostomy raised $70 \mathrm{~cm}$ from the ligament of Treitz (Fig. 1a). We then initiated total parenteral nutrition for nutritional support. As a result, progressive jaundice and repeated cholangitis had occurred. The endoscopy of the biliary cavity through the external drainage tube revealed necrotic tissue and sludge. Percutaneous transhepatic biliary drainage (PTBD) to biliary duct 3 was performed to treat the cholangitis. Computed tomography showed that the bulbus duodeni and biliary duct were in close contact with a distance of $2.7 \mathrm{~cm}$ (Fig. 2a, b). Surgical intervention was difficult because the length of the remaining intestine was very short. Therefore, we decided to perform MCA for biliaryduodenal anastomosis. The PTBD tube was gradually replaced with thicker ones up to $16 \mathrm{Fr}$. The daughter magnet was placed in the PTBD tube, and the parent magnet was positioned in the bulbus duodeni by a fiberscope

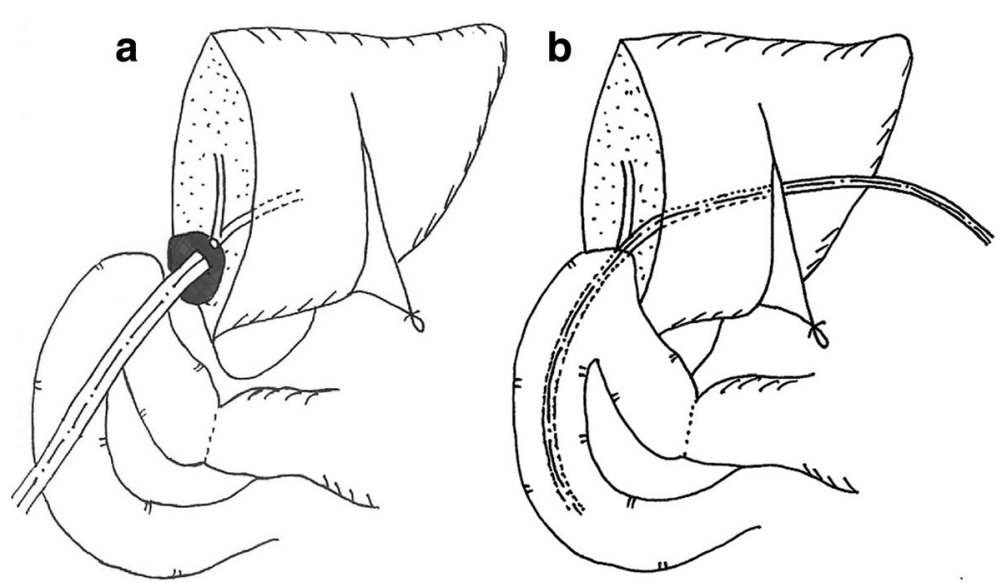

Fig. 1 Schema of anatomical relationship between the biliary duct and duodenum a before magnetic anastomosis and $\mathbf{b}$ after anastomosis. a External drainage tube was placed in the biliary cavity and $\mathbf{b}$ PTBD tube was placed over the anastomosis 


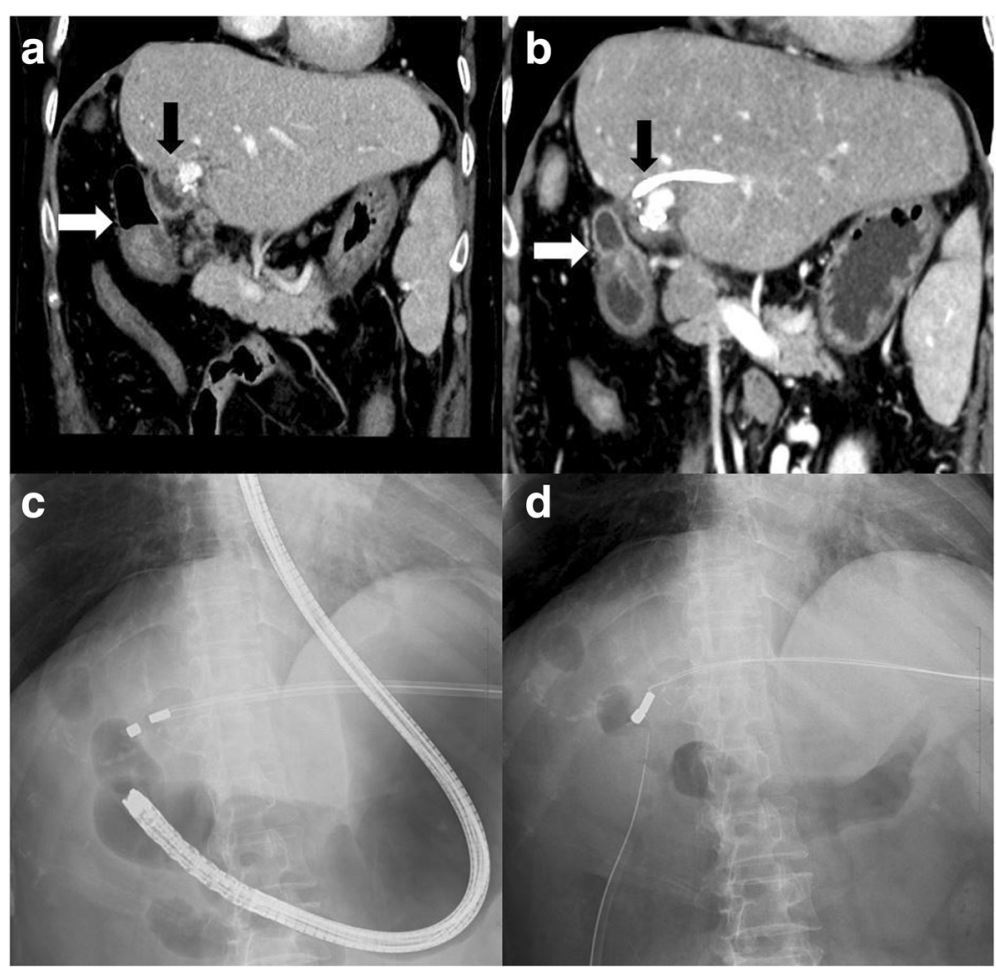

Fig. 2 a Computed tomography showed the bulbus duodeni (white arrow) and biliary duct (black arrow) come in contact with each other. $\mathbf{b}$ PTBD tube was placed into B3. c The parent magnet was inserted from PTBD tube, and daughter magnet was placed by gastrointestinal endoscopy. $\mathbf{d}$ The parent and daughter magnets connected sandwiching the biliary wall and duodenal wall

(Fig. 2c, d). Anastomosis between the left hepatic duct and the duodenum was established after 25 days, and the PTBD tube was placed over the anastomosis to prevent re-stenosis (Fig. 1b). In addition, a closure of the jejunostomy with side-to-side anastomosis was performed in the adaptive period while the capacity of the remaining intestine was at its maximum level. The results of sequential serum laboratory testing of the hepatobiliary enzymes and transition of the nutritional indexes are shown in Fig. 3. Serum levels of total bilirubin, aspartate aminotransferase, and alanine transaminase decreased after MCA and closure of the ileostomy. The body weight and serum level of albumin and choline esterase were maintained during hospitalization. The frequency of watery diarrhea decreased, and the patient was discharged 2 weeks after the closure of the ostomy without requiring parenteral nutrition. The PTBD tube was removed 11 months after the MCA (Fig. 4). After which, we looked at no stenosis of the anastomosis and improvement of hepatic function and nutritional indexes.

\section{Discussion}

MCA is a minimally invasive procedure for the management of biliary strictures and obstruction without surgical intervention. Procedure-related complications are seldom observed, and the results of anastomotic patency are uneventful compared with conventional surgery [5]. Because MCA is an interventional procedure, it can be performed on elderly patients, those with poor general condition or who have history of multiple laparotomy. To our knowledge, this is the first report of choledochoduodenostomy with MCA after major resection of the small intestine. This is a less invasive and safer procedure for the patients who do not have enough intestine for reconstruction of the biliary duct compared with conventional surgical procedure. In our case, the preserved intestine was so short (only $70 \mathrm{~cm}$ including the ileocecal valve) that it would have been difficult to anastomose the biliary duct to the intestine surgically. Endoscopic ultrasonographyguided hepaticogastrostomy could be a treatment option for this case. The rate of postoperative cholangitis in hepaticogastrostomy is much higher than that of choledochoduodenostomy [9]. Retrograde cholangitis can cause potentially fatal septicemia after LDLT, so we chose choledocoduodenostomy with MCA. Maintaining both the length and condition of the remaining intestine was also an important factor for the patient's long-term nutritional condition, allowing her to function without the need for parenteral nutrition.

Short bowel syndrome (SBS) is a disabling condition characterized by the inability to maintain fluid, electrolyte, and nutrient balances after a major resection or loss 


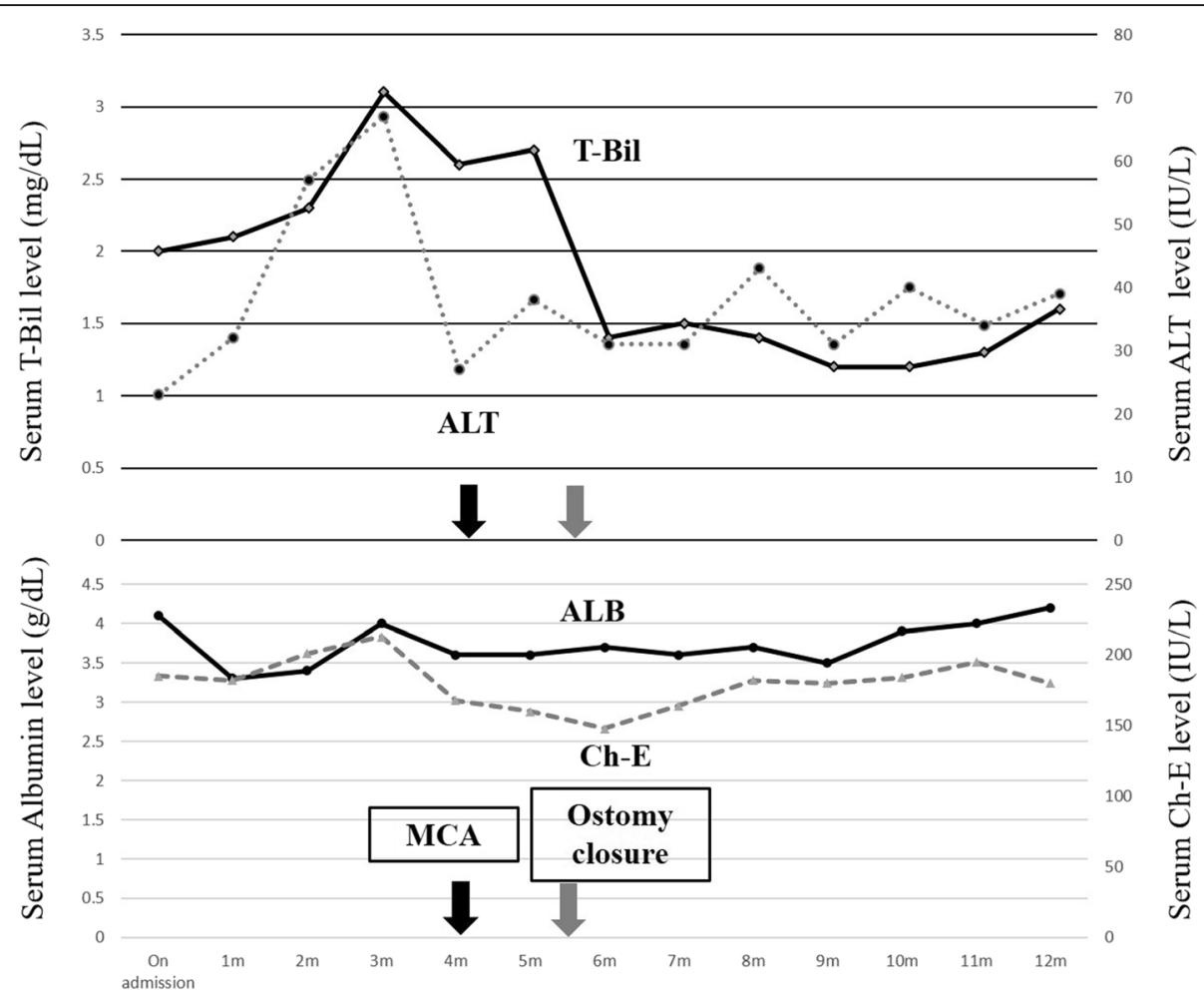

Fig. 3 The kinetics of the hepatobiliary enzymes and nutritional indexes

of function of the intestine [10]. Human intestine has the inherent ability to improve its absorptive capacity after a massive resection via increased intraluminal absorption and enteral neuro-hormonal stimuli, such as human growth hormone and glucagon-like peptide- 2 $[11,12]$. This change occurs over a period of weeks to several months after resection, known as the adaptive period [13]. External biliary drainage has a negative

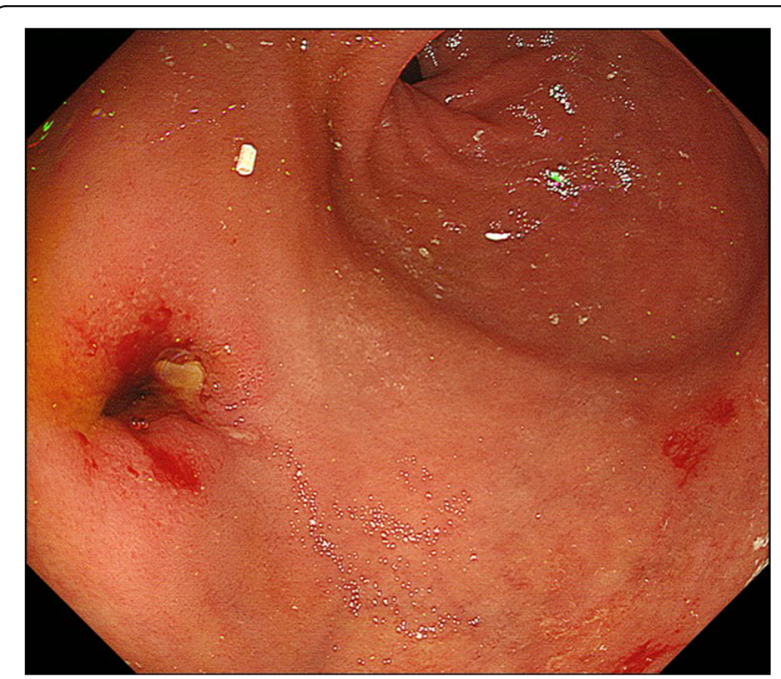

Fig. 4 Endoscopy showed no stenosis after removal of the PTBD stent impact on bile acid circulation, which is important for hepatic bile formation and absorption of dietary lipids and fat-soluble vitamins in the small intestine [14]. Internal drainage of bile with MCA has positive effects on the maintenance of the nutritional condition. Closure of the ostomy during this period, preservation of the ileocecal valve, preoperative nutritional support, side-toside anastomosis, and internal drainage of the bile all contributed to the control of watery diarrhea and recovery from malnutrition in this case.

Choledochoduodenostomy differs from the choledochoenterostomy or choledochocholedochostomy in that the magnets are used not for recanalization of the stenosis or obstruction but for creation of a new fistula. Alvalani et al. reported good results after choledochoduodenostomy with MCA for patients with a malignant obstruction [4]. The main complications after choledochoduodenostomy are sump syndrome and cholangitis. Sump syndrome occurs from bile stasis and reflux of duodenal contents into the biliary tree, resulting in cholangitis or hepatic abscess. Although the prevalence of sump syndrome is reported between 2.4 and $5 \%$ in previous studies, these cases can be managed safely and successfully with endoscopic procedure $[4,15,16]$. The rate of subsequent cholangitis after choledochoduodenostomy for benign obstruction is reported 0 to $1.1 \%$, which is extremely lower than the rate after hepaticogastrostomy or drainage using plastic stent $[9,15,17]$. 


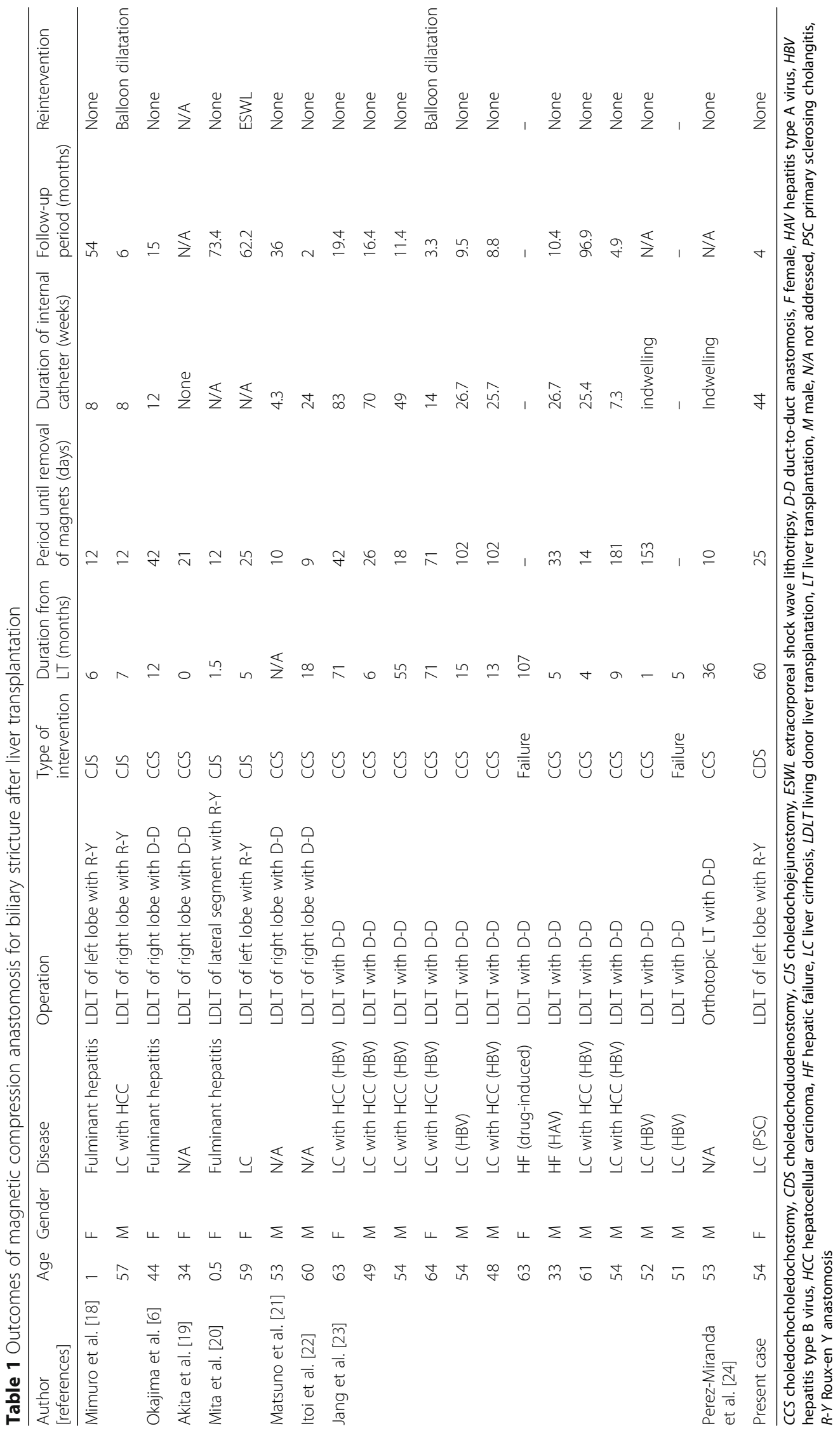


This is the first report of choledochoduodenostomy using magnetic compression after liver transplantation. In addition, there is no report of choledochoduodenostomy after major resection of the small intestine. To our knowledge, only 22 cases, including our case, of MCA after liver transplantation for biliary stricture have been reported (Table 1) $[6,18-24]$. The median age of the patients was 53.5 years (range 0.5-64 years), and 13 patients were male. Liver transplantation was performed for liver cirrhosis (LC) with hepatocellular carcinoma (HCC) in nine patients, for LC with viral infection in three patients, and for fulminant hepatitis in three patients. Choledochocholedochostomy was carried out for these patients after duct-to-duct anastomosis, and choledochojejunostomy was done after duct-to-jejunum anastomosis. MCA failed in two patients: One patient developed relatively distance from the anastomosis site, and the other had diffuse narrowing and torsion of the common biliary duct, which made it impossible to place the parent magnet. Distance between the two magnets is a very important factor for successful intervention, because the strength of the magnets gets weaker as the distance gets longer [5]. Preoperative imaging study is necessary to investigate the distance between the biliary duct and intestine and also to avoid trapping the blood vessels between the two magnets. Median follow-up period reported was only 11.4 months, so further careful follow-up is necessary to determine the long-term outcome after MCA. It is reported that PSC is strongly associated with inflammatory bowel disease (IBD); in fact, its rate of incidence among patients with IBD is $75 \%$ [1]. The UC of our patient was well controlled with oral aminosalicylates and methylprednisolone. Patients with both PSC and UC have a high risk of colon cancer; therefore, careful follow-up with colonoscopy is indicated to prevent further resection of the intestine [25].

\section{Conclusions}

Biliary-duodenal anastomosis could be an alternative method for the management of biliary stricture or obstruction. In addition, MCA could be a less invasive method for treatment of biliary stricture that cannot be accessed by conventional surgery. Careful follow-up of these cases should be done to determine the long-term patency and complications in these patients.

\section{Abbreviations \\ LDLT: Living donor liver transplantation; MCA: Magnetic compression anastomosis; PSC: Primary sclerosing cholangitis; PTBD: Percutaneous transhepatic biliary drainage; UC: Ulcerative colitis}

\section{Acknowledgements}

We like to thank the Hiroshima University Center of Life Sciences for the use of its facilities.

\section{Funding}

Not applicable.

\section{Availability of data and materials}

The data supporting the conclusions of this article are included within the article. A copy of the written consent is available for review by the Editor-inChief of this journal.

\section{Authors' contributions}

$\mathrm{HT}$ is the corresponding author and carried out the revision of the manuscript. Kentaro I, Kohei I, and TK participated in the surgery. SS and MO participated in the clinical treatments. $\mathrm{HO}$ supervised the writing of the manuscript. All authors read and approved the final manuscript.

\section{Competing interests}

The authors declare that they have no competing interests.

\section{Consent for publication}

Written informed consent was obtained from the patient for the publication of this case report and any accompanying images.

Ethics approval and consent to participate Not applicable.

\section{Publisher's Note}

Springer Nature remains neutral with regard to jurisdictional claims in published maps and institutional affiliations.

Received: 10 March 2017 Accepted: 17 May 2017

Published online: 25 May 2017

\section{References}

1. Angulo P, Lindor KD. Primary sclerosing cholangitis. Hepatology. 1999;30: 325-32.

2. Umeshita $K$, Inomata $Y$, Furukawa $H$ et al. Liver transplantation in Japan -Registry by the Japanese Liver Transplantation Society. Hepatol Res. 2016; 46:1171-86

3. Muraoka N, Uematsu $H$, Yamanouchi $E$, et al. Yamanouchi magnetic compression anastomosis for bilioenteric anastomotic stricture after livingdonor liver transplantation. J Vasc Interv Radiol. 2005:16:1263-67.

4. Avaliani M, Chigogidze N, Nechipai A, Dolgushin B. Magnetic compression biliary-enteric anastomosis for palliation of obstructive jaundice: initial clinical results. J Vasc Interv Radiol. 2009;20:614-23.

5. Itoi T, Kasuya K, Sofuni A, et al. Magnetic compression anastomosis for biliary obstruction: review and experience at Tokyo Medical University Hospital. J Hepatobiliary Pancreat Sci. 2011;18:357-65.

6. Okajima H, Kotera A, Takeichi T, et al. Magnet compression anastomosis for bile duct stenosis after duct-to-duct biliary reconstruction in living donor liver transplantation. Liver Transpl. 2005;11:473-75.

7. Kamiya S, Nagino M, Kanazawa $H$, et al. The value of bile replacement during external biliary drainage: an analysis of intestinal permeability, integrity, and microflora. Ann Surg. 2004;239:510-7.

8. Saiki S, Chijiiwa K, Komura M, et al. Preoperative internal biliary drainage is superior to external biliary drainage in liver regeneration and function after hepatectomy in obstructive jaundiced rats. Ann Surg. 1999;230:655-62.

9. Soulez $\mathrm{G}$, Thérasse $\mathrm{E}$, Oliva $\mathrm{VL}$, et al. Left hepaticogastrostomy for biliary obstruction: long-term results. Radiology. 1997;204:780-6.

10. Amiot A, Messing B, Corcos $\mathrm{O}$, et al. Determinants of home parenteral nutrition dependence and survival of 268 patients with non-malignant short bowel syndrome. Clin Nutr. 2013;32:368-74.

11. Byrne $T A$, Persinger $R L$, Young $L S$, et al. A new treatment for patients with short-bowel syndrome. Growth hormone, glutamine, and a modified diet. Ann Surg. 1995;222:243-54.

12. Drucker DJ, Erlich P, Asa SL, Brubaker PL. Induction of intestinal epithelial proliferation by glucagon-like peptide 2. Proc Natl Acad Sci U S A. 1996;93: 7911-16.

13. Wilmore DW, Robinson MK. Short bowel syndrome. World J Surg. 2000;24 1486-92.

14. Lefebvre $P$, Cariou B, Lien F, et al. Role of bile acids and bile acid receptors in metabolic regulation. Physiol Rev. 2009;89:147-91.

15. Leppard WM, Shary TM, Adams DB, et al. Choledochoduodenostomy: is it really so bad? J Gastrointest Surg. 2011;15:754-57.

16. Mavrogiannis C, Liatsos C, Romanos A, et al. Sump syndrome: endoscopic treatment and late recurrence. Am J Gastroenterol. 1999;94:972-75. 
17. Degenshein GA. Choledochoduodenostomy: an 18 year study of 175 consecutive cases. Surgery. 1974;76:319-24.

18. Mimuro A, Tsuchida A, Yamanouchi E, et al. A novel technique of magnetic compression anastomosis for severe biliary stenosis. Gastrointest Endosc. 2003:58:283-87.

19. Akita $H$, Hikita $H$, Yamanouchi $E$, et al. Use of a metallic-wall stent in the magnet compression anastomosis technique for bile duct obstruction after liver transplantation. Liver Transpl. 2008;14:118-20.

20. Mita A, Hashikura Y, Masuda Y, et al. Nonsurgical policy for treatment of bilioenteric anastomotic stricture after living donor liver transplantation. Transpl Int. 2008;21:320-27.

21. Matsuno N, Uchiyama M, Nakamura Y, et al. A nonsuture anastomosis using magnetic compression for biliary stricture after living donor liver transplantation. Hepatogastroenterology. 2009;56:47-9.

22. Itoi T, Yamanouchi E, lkeuchi $\mathrm{N}$, et al. Magnetic compression duct-to-duct anastomosis for biliary obstruction in a patient with living donor liver transplantation. Gut Liver. 2010:4 Suppl 1:S96-8.

23. Jang $\mathrm{Sl}$, Kim JH, Won JY, et al. Magnetic compression anastomosis is useful in biliary anastomotic strictures after living donor liver transplantation. Gastrointest Endosc. 2011;74:1040-48.

24. Perez-Miranda M, Aleman N, de la Serna HC, et al. Magnetic compression anastomosis through EUS-guided choledochoduodenostomy to repair a disconnected bile duct in orthotopic liver transplantation. Gastrointest Endosc. 2014;80:520-21.

25. Broome U, Lofberg R, Veress B, Eriksson LS. Primary sclerosing cholangitis and ulcerative colitis: evidence for increased neoplastic potential. Hepatology. 1995;22:1404-08.

\section{Submit your manuscript to a SpringerOpen ${ }^{\circ}$ journal and benefit from:}

- Convenient online submission

- Rigorous peer review

- Open access: articles freely available online

- High visibility within the field

- Retaining the copyright to your article

Submit your next manuscript at $\boldsymbol{s p r i n g e r o p e n . c o m ~}$ 